\title{
BENIGN PAROXYSMAL POSITIONAL VERTIGO: OUR EXPERIENCE AT A TERTIARY CARE CENTRE OF CENTRAL INDIA
}

\begin{tabular}{|l|l|l|l}
\hline Neurology &
\end{tabular}

\section{Dr Patel Meghraj MBBS, M.D. (Medicine),D.M.(Neurology), Consultant Neurology, Siddhanta Red cross Singh* \\ Super speciality hospital Bhopal (M.P.), India. *Corresponding Author}

\section{ABSTRACT}

Background: Benign paroxysmal positional vertigo (BPPV) is a common cause of vertigo. The diagnosis is often delayed and patients are unnecessarily investigated and treated with drugs.

Aim: To analyze the patient profile, duration of symptoms, etiology, associated co-morbidities, type of canal involvement and response to CRP in cases of BPPV.

Material \& Methods: The present prospective study was conducted at a tertiary care centre from January 2015 to December 2016 in 90 patients with a clinical diagnosis of BPPV. Patient particular and disease specific data were recorded in preset profoma and analyzed. All these patients were treated by different CRP specific for the canal involved. All cases were reassessed for post procedural response.

Results: Total 90 patients were included in the study with age range of 20 to 76 year. Mean age was 46.74 . Maximum patients (26.67\%) were in the age range of 41-50 year with male: female was 1:1.43. The duration of symptoms was in from 2 days to more than 3 years. Most common morbidity was diabetes and most common cause was Idiopathic (82.22\%). Most of these patients presented with positional vertigo (94.44\%). Right posterior canal was involved in 52 cases $(57.78 \%)$ and left in $30(33.33 \%)$ cases.

Conclusion: BPPV is a common cause of vertigo. More awareness needed about its symptoms, early application of Dix-Hallpike test and Epley's procedure to reduce the suffering of patients and to reduce unnecessary diagnostic tests and costs.

KEYWORDS

\section{BPPV, Dix-Hallpike test, CRP.}

\section{INTRODUCTION:}

BPPV was first described by Barany in 1921, and he attributed the disorder to otolith disease. 'The clinical diagnosis of this disorder was not well defined until Dix and Hallpike described the classic positioning which causes a characteristic nystagmus. ${ }^{2}$ Benign paroxysmal positioning vertigo is a disorder characterized by brief attacks of vertigo, with associated nystagmus, precipitated by certain changes in head position with respect to gravity. ${ }^{3}$ Furthermore, BPPV is likely to be the most common vestibular disease as every third participant with vestibular vertigo had BPPV. The overall prevalence of BPPV is 10.7 to 140 per 100,000 populations. It is common in the age between 50 and 55 years in idiopathic cases ${ }^{6}$ and it is rarely seen in childhood. It is more commonly seen in older ages because of the degeneration of statoconia, arising from demineralization, shown in histopathology studies. ${ }^{7}$ Based on the theory of canalithiasis, Canalith Repositioning Procedure (CRP) was instituted at Portland Otologic Clinic in 1979. This was designed to treat BPPV throughout migration of free moving pathological densities in the endolymph of a semicircular canal using timed head maneuvers and applied vibration. ${ }^{8}$ This study will be plan to evaluate the prevalence, socio-demographic factors clinical presentation associate co-morbidities and response to the canalith repositioning procedures in cases of benign positional vertigo in central India.

\section{OBJECTIVES:}

1. To study the various socio-demographic characteristics and clinical presentation of cases with BPPV

2. To evaluate the site, associated symptoms and co-morbidities in cases with BPPV

3 . To analyse the response to the canalith repositioning procedures in cases with BPPV.

\section{MATERIAL \& METHODS:}

This prospective study was carried out in a tertiary care centre in central India from January 2015 to December 2016. All cases with rotatory dizziness on changing position attended in neurology clinic were evaluated. All cases were inquired about their age, duration of symptoms, side on which the symptoms develop, other symptoms as Positional vertigo, Nausea, Vomiting, Imbalance, Anxiety, Decreased sleep, ear ache or discharge, associated co-morbidities, history of head injury recorded in preset proformas. Suspected etiology of CNS cause was excluded from the study. BPPV was confirmed by Dix-Hallpike test, side lying test and roll test and all positive cases were enrolled for the study. Canalith repositioning procedure was performed and repeated three times immediate after the procedure, after 7 days and after 1 month in all the patients irrespective of nystagmus being present or absent to ensure complete removal of the particles. Response to Canalith repositioning procedure was entered into the preset proforma.
All data was statistical analyzed and conclusions were drawn.

Dix-Hallpike test: The examiner holds the seated patient's head $45^{\circ}$ to the left or right. This aligns the posterior semicircular canal in the vertical plane. The patient should be asked to hold onto the examiner's arm for stability. The examiner then drops the patient back to the supine position, with the head hanging down off the stretcher $10^{\circ}-30^{\circ}$. This causes a large rotation of the posterior semicircular canal within its own plane, moving the loose otolith and reproducing the symptoms. The test is considered positive if it provokes the characteristic torsional and vertical nystagmus.'

\section{RESULTS:}

Total 90 patients were included in the study with age range of 20 to 76 year. Mean age was 46.74 . Maximum patients $(26.67 \%)$ were in the age range of $41-50$ year followed by $24.44 \%$ in the $51-60$ year. In total 90 patients 37 were male and 53 were female with male:female was 1:1.43. The duration of symptoms was in from 2 days to more than 3 years. Maximum patients (55.55\%) presented within a months. Total 9 patients were presented after 6 months of symptoms onset.

Most common morbidity was diabetes in 13 patients followed by hypertension (12), hypothyroid (6), CAD (4), Eye surgery (5) and ear surgery (3). Etiology wise most patients were in Idiopathic category $(82.22 \%)$ followed by in post traumatic $(8.89 \%)$, migraine $(5.55)$ and meniere's disease (3.33).

In clinical presentation most of the patients presented with positional vertigo $(94.44 \%)$. Other symptoms were nausea $(51.11 \%)$, vomiting $(22.22 \%)$, imbalance $(38.89 \%)$, anxiety $(57.78 \%)$ and decreased sleep $(16.67 \%)$. Right posterior canal was involved in 52 cases $(57.78 \%)$ and left in $30(33.33 \%)$ cases. Posterior canal was involved in $87(96.67 \%)$ cases, horizontal canal in $3(3.33 \%)$ cases and anterior canal in 1 $(1.11 \%)$ case.

Tables:

Table1: Distribution Of Cases According To Personal Profile, Duration Of Disease And Associated Co-morbidities:

\begin{tabular}{|l|l|l|c|c|}
\hline S.N. & Variables & & Number & Percentage (\%) \\
\hline 1. & Gender & Male & 37 & 41.11 \\
\cline { 3 - 5 } & & Female & 53 & 58.89 \\
\hline \multirow{4}{*}{2.} & \multirow{2}{*}{ Age groups } & $\leq 30$ year & 4 & 4.44 \\
\cline { 3 - 5 } & & 31-40 year & 20 & 22.22 \\
\cline { 3 - 5 } & & $41-50$ year & 24 & 26.67 \\
\cline { 3 - 5 } & & 51-60 year & 22 & 24.44 \\
\cline { 3 - 5 } & & 61-70 year & 15 & 16.67 \\
\cline { 3 - 5 } & & $>70$ year & 5 & 5.55 \\
\hline
\end{tabular}




\begin{tabular}{|l|l|l|c|c|}
\hline 3. & Duration of & $<4$ weeks & 50 & 55.55 \\
\cline { 3 - 5 } & symptoms & $4-8$ weeks & 15 & 16.67 \\
\cline { 3 - 5 } & & $8-12$ weeks & 5 & 5.55 \\
\cline { 3 - 5 } & $12-16$ weeks & 4 & 4.44 \\
\cline { 3 - 5 } & $16-20$ weeks & 4 & 4.44 \\
\cline { 3 - 5 } & & $20-24$ weeks & 3 & 3.33 \\
\cline { 3 - 5 } & $>24$ weeks & 9 & 10 \\
\hline \multirow{4}{*}{4.} & \multirow{2}{*}{$\begin{array}{l}\text { Co- } \\
\text { morbidities }\end{array}$} & Diabetes mellitus & 13 & 14.44 \\
\cline { 3 - 5 } & Hypertension & 12 & 13.33 \\
\cline { 3 - 5 } & Hypothyroid & 6 & 6.67 \\
\cline { 3 - 5 } & CAD & 4 & 4.44 \\
\cline { 3 - 5 } & Eye surgery & 5 & 5.55 \\
\cline { 3 - 5 } & Ear surgery & 3 & 3.33 \\
\hline
\end{tabular}

Table 2: Distribution Of Cases According To Etiology, Clinical Features And Canal Involvement

\begin{tabular}{|c|c|c|c|c|c|}
\hline S.N. & \multicolumn{3}{|c|}{ Variables } & Number & Percentage (\%) \\
\hline \multirow[t]{4}{*}{1.} & \multirow[t]{4}{*}{ Etiology } & \multicolumn{2}{|c|}{ Idiopathic } & 74 & 82.22 \\
\hline & & \multicolumn{2}{|c|}{ Post Traumatic } & 8 & 8.89 \\
\hline & & \multicolumn{2}{|l|}{ Migraine } & 5 & 5.55 \\
\hline & & \multicolumn{2}{|c|}{ Meniere's disease } & 3 & 3.33 \\
\hline \multirow[t]{6}{*}{2.} & \multirow{6}{*}{$\begin{array}{l}\text { Clinical } \\
\text { features }\end{array}$} & \multicolumn{2}{|c|}{ Positional vertigo } & 85 & 94.44 \\
\hline & & \multicolumn{2}{|l|}{ Nausea } & 46 & 51.11 \\
\hline & & \multicolumn{2}{|l|}{ Vomiting } & 20 & 22.22 \\
\hline & & \multicolumn{2}{|c|}{ Imbalance } & 35 & 38.89 \\
\hline & & \multicolumn{2}{|l|}{ Anxiety } & 52 & 57.78 \\
\hline & & \multicolumn{2}{|c|}{ Decreased sleep } & 15 & 16.67 \\
\hline \multirow[t]{6}{*}{3.} & \multirow{6}{*}{$\begin{array}{c}\text { Canal } \\
\text { involvement }\end{array}$} & \multirow{3}{*}{$\begin{array}{l}\text { Posterior } \\
\text { canal }\end{array}$} & Right & 52 & 57.78 \\
\hline & & & Left & 30 & 33.33 \\
\hline & & & Bilateral & 5 & 5.55 \\
\hline & & \multicolumn{2}{|c|}{ Horizontal } & 3 & 3.33 \\
\hline & & \multicolumn{2}{|l|}{ Anterior } & - & - \\
\hline & & \multicolumn{2}{|l|}{ Mixed } & - & - \\
\hline
\end{tabular}

Table 3: Distribution Of Cases According To Response Of Canalith Repositioning Procedure

\begin{tabular}{|l|l|l|l|l|l|l|l|}
\hline \multirow{2}{*}{$\begin{array}{l}\text { SN } \\
\text { CRP }\end{array}$} & Response of & \multicolumn{2}{l}{$\begin{array}{l}\text { Immediate after } \\
\text { CRP }\end{array}$} & 7 days & \multicolumn{2}{l|}{ 1 month } \\
\cline { 3 - 8 } 1. & $\begin{array}{l}\text { Complete } \\
\text { relief }\end{array}$ & 82 & 91.11 & 80 & 88.88 & 69 & 76.66 \\
\hline 2. & Partial relief & 8 & 8.88 & 8 & 8.88 & 13 & 14.44 \\
\hline 3. & No relief & - & - & - & - & - & - \\
\hline 4. & Recurrence & - & - & 2 & 2.22 & 8 & 8.88 \\
\hline
\end{tabular}

\section{DISCUSSION:}

Although BPPV is a one of the most common cause of vertigo, still it is under-recognized by non-specialist due to misbelieve as vertigo is a common presentation of cervical spondylosis, which is commonly seen in elderly population as such, is diagnosed late. There is a long delay between onset of symptoms and diagnosis, often with multiple healthcare contacts. Hence, it is important to increase awareness of primary care giving physician about this condition as it can be easily diagnosed by a simple bed side Dix-Hallpike test and can be treated easily by canalith repositioning procedures.

BPPV is known to affect all age groups, though it appears to be more common in the elderly in 5th to 7th decade of life and rarely seen in children. In our study, the mean age of the participants was 46 year with maximum number of patients in the age group of 41 to 50 years $(26.67 \%)$ contrary to the literature. ${ }^{10,11,12}$ The reason for younger age in our study may be due to younger patients are seeking more medical help. In present study the sex distribution indicates a predilection for women which is similar to other studies..$^{10,12}$

In the present study the most common cause was idiopathic ( $82.22 \%)$ followed by trauma $(8.89 \%)$, migraine $(5.55 \%)$, and ipsilateral Menier's disease $(3.33 \%)$. Similarly, in the literature in most of the cases the cause of BPPV is idiopathic and the most common identified etiologies are previous trauma, ipsilateral Meniere's disease, ipsilateralvestibular neuritis and severe systemic disease. ${ }^{13,14,15}$ In our study the most common presentation was positional rotatory vertigo $(94.44 \%)$. Other symptoms were nausea $(51.11 \%)$, vomiting (22.22\%), and imbalance (38.89\%). In the study by Kentala E et al reported that $80 \%$ of patients experience a rotatory vertigo and $47 \%$ presents with floating sensation."
In our study only $55.55 \%$ of patients are presented within one month of symptoms onset. There was delay in the diagnosis in remaining $45.45 \%$ of patients. Almost $10 \%$ of patients are presented after six months of onset of symptoms. In the study by Wang $\mathrm{H}$ et al found that the average time between first symptoms and diagnosis was 70 months, with an average of eight hospital visits. ${ }^{17}$ The delay in diagnosis of BPPV is due to lack of clinician's awareness of this lesion. The delayed diagnosis is sometimes attributed to the atypical presentation of BPPV. Most common co-morbidity associated in our study was diabetes in $13 \%$ patients followed by hypertension $(13.33 \%)$. Similarly, Diabetes was found to be unusually prevalent in BPPV patients in a study done by Cohen et al. ${ }^{18}$

In present study posterior canal was involved in 87 (96.67\%) cases, horizontal canal involved in $2(2.22 \%)$ cases and anterior canal in 1 $(1.11 \%)$ case. In a study conducted by SotoVarela A et at on 614 patients of BPPV posterior semicircular canal was affected in 543 cases $(88.4 \%)$, the horizontal in $39(6.4 \%)$ and the superior canal in 32 $(5.2 \%)$.

In our study right posterior canal is more commonly affected than left which is consistent with studies conducted by Brevern $\mathrm{MV}$ et $\mathrm{al}^{20}$, Marciano E et al ${ }^{21}$ and Soto-Varela A et $\mathrm{al}^{13}$. However, Gaur S et a ${ }^{10}$ had left ear predilection in their study. This is proposed to be due to increased preference of sleeping in the right lateral position. ${ }^{20}$

In the present study the success rate of Epley's maneuver was $92 \%$ with complete relief of symptoms within 24 hours. There is no relief of symptoms in $2.22 \%$ of patients after 1 week and in $8.88 \%$ of patients after 1 month. Horizontal canal BPPV patient were treated with barbecue roll method. In the study conducted by Epley on 30 patients with BPPV, there was $90 \%$ cure rate seen after the maneuver. ${ }^{22}$ Similar study was conducted by Parnes et al. in 1993 on 38 patients with BPPV based on positive Dix Hallpike test and symptoms of BPPV and observed a cure rate of $68.5 \%$.

There are chances of recurrence of BPPV after complete resolution and hence it is recommended that the patient should be told about a likelihood of recurrences and the patient should be periodically reassessed after the treatment. ${ }^{12,23}$

\section{CONCLUSION:}

BPPV is a common cause of vertigo. In our study It is more common in female and in their fifth decade. Patients usually present with positional rotatory vertigo. Dix-hallpike test should be commonly used in clinic where there is a suspicion of BPPV. The diagnosis sometimes delayed up to 6 months. Posterior canal involvement is most common followed by horizontal. Causes were idiopathic in majority followed by trauma. Canalith repositioning procedure is very effective in treatment with very low risk of recurrence.

\section{REFERENCES:}

Barany E. Diagnosis of disease manifestations in the otolithic apparatus. Acta OtoLaryngologica. 1920;2(3): 434-437. doi: 10.3109/00016482009123103.

2. Dix M. R., Hallpike C. S. The pathology, symptomatology and diagnosis of certain common disorders of the vestibular system. Annals of Otology, Rhinology \& Laryngology. 1952;61(4):987-1016. doi: 10.1177/000348945206100403.

3. Parnes L. S., Agrawal S. K., Atlas J. Diagnosis and management of benign paroxysma positiona 1 vertigo (BPPV) Canadi an Medi c a 1 Assoc i a tionJourna 1. 2003; 169 (7) 681-693.

4. van der Zaag-Loonen HJ, van Leeuwen RB, et al. Prevalence of unrecognized benign paroxysmal positional vertigo in older patients. Eur Arch Otorhinolaryngol. 2015 Jun; 272 (6):1521-4. doi: 10. 1007/s00 405-014-3409-4. Epub 2014 Dec 9.

5. Von Brevern M, Radtke A, Lezius F, Feldmann M, Ziese T, Lempert T, Neuhauser H. Epidemiology of benign paroxysmal positional vertigo: a population based study. Journal of Neurology, Neurosurgery \& Psychiatry. 2007;1;78(7):710-715

6. Hilton M, Pinder D. The Epley manoeuvre for benign paroxysmal positional vertigo - a Hilton M, Pinder D. The Epley manoeuvre for benign paroxysmal po
systematic review. Clin Otolaryngol Allied Sci.2002;27(6):440-445.

systematic review. Clin Otolaryngol Allied Sci.2002; $27(6): 440-445$.
Walther LE, Westhofen M. Presbyvertigo-aging of otoconia and ves - tibular sensory cells. J Vestib Res. 2007; 17(2-3):89-92

8. Celebisoy N, Polat F, Akyurekli O (2008) Clinical features of benign paroxysma positional vertigo in Western Turkey. Eur Neurol 59(6):315-319

Viirre E, Purcell I, Baloh RW. The Dix-Hallpike test and the canalith repositioning maneuver. Laryngoscope. 2005;115:184-7.

10. Gaur S, Awasthi SK, Bhadouriya SK, et al. Efficacy of Epley's Maneuver in Treatin BPPV Patients: A Prospective Observational Study. Int J Otolaryngol. 2015; 2015: BP 160 . di: 10.1155/2015/487160. Epub2015 Oct1.

11. Bhattacharyya N, Baugh RF, Orvidas L, et al. Clinical practice guideline: benign paroxysmal positional vertigo. Otolaryngol Head Neck Surg. 2008 Nov; 139 (5 Supp 4):S47-81. doi: 10.1016/j.otohns. 2008.08.022

12. Tang H, Li W. Advances in the diagnosis and treatment of benign paroxysmal positional vertigo. Exp Ther Med. 2017 Sep;14(3):2424-2430. doi: 10.3892/ etm. 2017.4837. Epub 2017 Jul 25.

13. Soto Varela A, BartualMagro J, Santos Pérez S, et al. Benign paroxysmal vertigo: comparative prospective study of the efficacy of Brandt and Daroff exercises, Semont and Epley maneuver. Rev LaryngolOtolRhinol(Bord). 2001;122(3):179-83.

14. Davies RA, Luxon LM. Dizziness following head injury: a neuro-otological study. J 
Neurol. 1995 Mar; 242 (4):222-30.
15. Gyo K. Benign paroxysmal positional vertigo as a complication of postoperative bedrest. Laryngoscope. 1988 Mar;98(3):332-3. DOI:10.1288/00005537-198803000-00019.

16. Kentala E, Pyykko I. Vertigo in patients with benign paroxysmal positional vertigo. Acta Otolaryngol Suppl. 2000;543:20-22.

17. Wang H. Yu D. Song N. Su K. Yin S. Delayed diagnosis and treatment of benign paroxysmal positional vertigo associated with current practice. Eur Arch Otorhinolaryngol. 2014;271:261-4

18. Cohen HS, Kimball KT (2005) Effectiveness of treatments for benign paroxysmal positional vertigo of the posterior canal. Otol Neurotol 26(5):1034-1040

19. Soto-Varela A, Santos-Perez S, Rossi-Izquierdo M, et al. Are the three canals equally susceptible to benign paroxysmal positional vertigo? AudiolNeurootol. 2013; 18 (5):327-34. doi: 10.1159/000354649. Epub 2013 Sep 28

20. von Brevern $\mathrm{M}$, Seelig T, Neuhauser $\mathrm{H}$, et al. Benign paroxysmal positional vertigo pred Bever M, Seelig T, Newhauser H, et al. Bengn paroxysmal po predominantly affects the right labyrinth. J Neurol Neurosurg Psychiatry. 2004 Oct; 75 (10): 1487-8. DOI: $10.1136 /$ jnnp. 2003.031 500.

21. Marciano E, Marcelli V. Postural restrictions in labyrintholithiasis. Eur Arch Otorhinolaryngol. 2002 May; 259 (5):262-5. Epub 2002 Mar 19. DOI:10. 1007/s00405001-0445-7

22. Epley JM. The canalith repositioning procedure: for treatment of benign paroxysmal positional vertigo. Otolaryngol Head Neck Surg. 1992 Sep;107(3):399- 404

23. Parnes LS, Price-Jones RG. Particle repositioning maneuver for benign paroxysmal positional vertigo. Ann OtolRhinolLaryngol. 1993 May; 102(5):325-31. 